\title{
Bench Comparative Assessment of Mechanically Assisted Cough Devices
}

\author{
Pamela Frigerio PT, Federico Longhini MD, Maurizio Sommariva PT, Enrica G Stagni PT, \\ Francesco Curto MD, Tiziana Redaelli MD, Marco Ciboldi DEng, Anita K Simonds MD, \\ and Paolo Navalesi MD
}

\begin{abstract}
BACKGROUND: Mechanically assisted cough devices are used in patients with impaired cough to avoid secretion accumulation. We compared 5 mechanically assisted cough devices by bench testing using a breathing simulator and assessed their user-friendliness. METHODS: We measured inspiratory and expiratory airway pressures and peak expiratory flow, the strongest indicator of cough efficacy. We performed 2 bench tests: 1) to ascertain the differences between preset and actual settings in 3 different machines of each mechanically assisted cough device and 2) to assess the effects of varying respiratory impedance and air leaks on performance of the devices. We also evaluated the user-friendliness of the devices by measuring the time required and errors in accomplishing 4 tasks by 10 physicians unfamiliar with mechanically assisted cough devices compared with product specialists from the distributing companies. Physicians also scored the ease of use. RESULTS: Four mechanically assisted cough devices during insufflation and all 5 during exsufflation showed differences between preset and actual airway pressures. All but one device showed uneven actual pressure values between models of the same type. Peak expiratory flow was significantly influenced by the mechanical properties in 2 devices and by air leaks in 4 devices. The median time to accomplish all tasks by the product specialist (10 [interquartile range of 2-29] s) was overall significantly shorter compared with all physicians (from 19 [14-65] to 36 [19-116] s). The number of procedural errors, but not the perceived ease of use, differed significantly between the devices. CONCLUSIONS: The performance of different mechanically assisted cough devices was erratic and included variance between models from the same manufacturer; it was affected by respiratory system impedance and air leaks. Time and rate of errors for performing procedures were elevated. These findings indicate that the devices are not interchangeable and that the settings should be targeted for each patient with the specific machine being used. Improvements in reliability, performance, and user-friendliness are advisable. Key words: cough; physical therapy modalities; respiratory therapy; pulmonary medicine; mechanical ventilators; critical care. [Respir Care 2015;60(7):975-982. () 2015 Daedalus Enterprises]
\end{abstract}

\section{Introduction}

Impaired cough with retention of tracheobronchial secretions is a common complication of neuromuscular dis-

\footnotetext{
Ms Frigerio, Ms Stagni, and Dr Redaelli are affiliated with the Spinal Cord Unit; Mr Sommariva and Dr Curto are affiliated with the Neurocritical Care Unit, Department of Neuroscience; and Dr Ciboldi is affiliated with Department of Clinical Engineering, Niguarda Cà Granda Hospital, Milan, Italy. Drs Longhini and Navalesi are affiliated with the Department of Translational Medicine, Eastern Piedmont University A. Avogadro, Novara, Italy, and the Division of Anaesthesia and Intensive
}

orders. Ineffective cough can lead to tracheotomy for the sole purpose of airway suctioning in patients with severe respiratory failure. ${ }^{1}$ Accordingly, intensive chest physical

\footnotetext{
Care, Sant'Andrea Hospita (ASL VC), Vercelli, Italy. Dr Simonds is affiliated with the National Heart \& Lung Institute Respiratory Biomedical Research Unit, Royal Brompton \& Harefield NHS Foundation Trust, London, United Kingdom. Dr Navalesi is also affiliated with CRRF Mons Luigi Novarese, Moncrivello, Italy.
}

Supplementary material related to this paper is available at http:// www.rcjournal.com. 


\section{Mechanically Assisted Cough Devices}

therapy, including cough assistance, is often prescribed to enhance secretion clearance. ${ }^{2,3}$

Cough assistance is traditionally based on inspiratory volume increase and manual abdominal thrust and/or chest compression. Mechanically assisted cough devices can also be used for this purpose, with either an endotracheal artificial airway $^{4}$ or a mask. ${ }^{5}$ These devices sequentially apply positive and negative (subatmospheric) pressure to the airway, creating a pressure gradient to promote a peak expiratory flow (PEF) sufficient to remove secretions from the large airways.

\section{See the Related Editorial on Page 1081}

Several studies have demonstrated the effectiveness of mechanically assisted cough devices and, in some cases, superiority to manual techniques ${ }^{6-8}$ in achieving secretion clearance in both acute ${ }^{9,10}$ and chronic ${ }^{11,12}$ subjects with ineffective cough with shorter periods of treatment. ${ }^{13}$ As a result, these devices are being increasingly used, and their commercial availability in Europe has risen concomitantly. The use of mechanically assisted cough devices has been proposed for ICU patients as a means to facilitate successful extubation. ${ }^{9}$

Despite the increased availability of mechanically assisted cough devices, to our knowledge, no study has evaluated and compared different devices to ascertain whether their performances are equivalent. As the performances of other devices such as home ventilators have been shown in bench studies to vary significantly, ${ }^{14}$ we designed this bench study to evaluate and compare 5 mechanically assisted cough devices that are commercially available in Europe with respect to reliability, intra-device reproducibility, and response to varying respiratory mechanics and presence of air leaks. Moreover, considering the lack of homogeneity among mechanically assisted cough devices with respect to control screens and buttons, we also evaluated the userfriendliness of these 5 devices for ICU physicians.

\section{Methods}

The study was performed on 2 consecutive days in November 2012 in the laboratory of the Department of Clinical Engineering at the Niguarda Cà Granda Hospital in

Dr Navalesi has disclosed relationships with Intersurgical, Maquet, Dräger, Breas, Covidien, GlaxoSmithKline, Hill-Rom, and Linde AG. Dr Simonds has disclosed a relationship with ResMed. The other authors have disclosed no conflicts of interest.

Correspondence: Paolo Navalesi MD, Department of Translational Medicine, Eastern Piedmont University A. Avogadro, Via Solaroli 17, 28100

Novara, Italy. E-mail: paolo.navalesi@med.unipmn.it.

\section{QUICK LOOK}

\section{Current knowledge}

Impaired cough with retention of secretions is a common complication of neuromuscular disease. Ineffective cough can lead to tracheostomy to facilitate airway suctioning in patients with respiratory failure. Intensive chest physical therapy, including cough assistance, is indicated to enhance secretion clearance. Mechanically assisted cough devices sequentially apply positive and negative pressure to the airway, creating a pressure gradient and enhancing peak expiratory flow to remove airway secretions.

\section{What this paper contributes to our knowledge}

The performance of different mechanically assisted cough devices in a model system varied widely. Devices from the same manufacturers performed differently. Changes in respiratory system impedance and air leaks significantly impacted device performance. Ease of use and time to set up the devices also differed greatly. Improved reliability of mechanically assisted cough devices is needed.

Milan, Italy. The 5 mechanically assisted cough devices tested are listed in Table 1. The devices were connected to a breathing simulator (ASL 5000, IngMar Medical, Pittsburgh, Pennsylvania). Two different bench tests were conducted. Both tests were performed in automatic mode, with the inspiratory and expiratory airway pressures $\left(\mathrm{P}_{\mathrm{aw}}\right)$ set at -40 and $+40 \mathrm{~cm} \mathrm{H}_{2} \mathrm{O}$, respectively, and the inspiratory $\left(\mathrm{T}_{\mathrm{I}}\right)$ and expiratory $\left(\mathrm{T}_{\mathrm{E}}\right)$ times both set $3 \mathrm{~s}$, without pause in between. Immediately after the first cycle of insufflation-exsufflation, 5 consecutive respiratory cycles were recorded and averaged. Both bench tests were performed once by the same bioengineer in the Laboratory of Clinical Engineering, without familiarity with the devices under evaluation. In addition, we performed a test to evaluate the user-friendliness of the 5 devices.

Table 1. Mechanically Assisted Cough Devices Tested in This Study

\begin{tabular}{lc}
\hline \hline \multicolumn{1}{c}{ Ventilator } & \multicolumn{1}{c}{ Manufacturer } \\
\hline Nippy cough assistor & B\&D Electromedical \\
& (Warwickshire, UK) \\
CoughAssist & Philips Healthcare (Best, The \\
& Netherlands) \\
New Negavent DA-3 PLUS Pegaso & Dima Italia (Bologna, Italy) \\
New Negavent DA-3 PLUS Mini & Dima Italia \\
Pegaso & Siare Engineering International \\
Pulsar & Group (Bologna, Italy) \\
&
\end{tabular}




\section{Mechanically Assisted Cough Devices}

\section{Bench Test 1}

Three different machines of each mechanically assisted cough device were tested in a single experimental condition (simulated compliance of $40 \mathrm{~mL} / \mathrm{cm} \mathrm{H}_{2} \mathrm{O}$, simulated resistance of $10 \mathrm{~cm} \mathrm{H}_{2} \mathrm{O} / \mathrm{L} / \mathrm{s}$, no air leaks).

\section{Bench Test 2}

We used the best performing of the 3 machines evaluated in bench test 1 for each mechanically assisted cough device. The response to varying simulated respiratory mechanical properties, with and without air leaks, was evaluated mimicking 4 conditions: (1) compliance of $40 \mathrm{~mL} / \mathrm{cm} \mathrm{H}_{2} \mathrm{O}$ and resistance of $10 \mathrm{~cm} \mathrm{H}_{2} \mathrm{O} / \mathrm{L} / \mathrm{s}$ without air leaks, (2) compliance of $40 \mathrm{~mL} / \mathrm{cm} \mathrm{H}_{2} \mathrm{O}$ and resistance of $10 \mathrm{~cm} \mathrm{H} \mathrm{H}_{2} \mathrm{O} / \mathrm{L} / \mathrm{s}$ with air leaks, (3) compliance of $60 \mathrm{~mL} / \mathrm{cm} \mathrm{H}_{2} \mathrm{O}$ and resistance of $20 \mathrm{~cm} \mathrm{H}_{2} \mathrm{O} / \mathrm{L} / \mathrm{s}$ without air leaks, and (4) compliance of $60 \mathrm{~mL} / \mathrm{cm} \mathrm{H}_{2} \mathrm{O}$ and resistance of $20 \mathrm{~cm} \mathrm{H}_{2} \mathrm{O} / \mathrm{L} / \mathrm{s}$ with air leaks.

\section{User-Friendliness Test}

One product specialist for each mechanically assisted cough device, indicated by the company distributors, and 10 physicians, randomly drawn by lot from the neuro-ICU medical staff and without previous experience with any of the 5 devices under evaluation, were selected to test userfriendliness. One week before the test, the physicians received information on the functions of all 5 devices. ${ }^{15}$ Physicians were asked to perform a 4-task test for each mechanically assisted cough device. The order of evaluation of the devices was randomized for each physician. The test consisted of 4 separate phases: (1) start-up (starting the assembled device), (2) recognizing parameters (inspiratory and expiratory $\mathrm{P}_{\mathrm{aw}}, \mathrm{T}_{\mathrm{I}}, \mathrm{T}_{\mathrm{E}}$, and the pause in between, requested according to a randomized sequence), (3) varying settings (inspiratory $\mathrm{P}_{\text {aw }}$ of $40 \mathrm{~cm} \mathrm{H}_{2} \mathrm{O}$, expiratory $\mathrm{P}_{\mathrm{aw}}$ of $-40 \mathrm{~cm} \mathrm{H}_{2} \mathrm{O}, \mathrm{T}_{\mathrm{I}}$ of $4 \mathrm{~s}, \mathrm{~T}_{\mathrm{E}}$ of $3 \mathrm{~s}$, pause of $1 \mathrm{~s}$ ), and (4) stop (ie, turning off the machine and activating the standby mode, if available).

\section{Data Analysis}

Data of the 2 bench tests were recorded from the ASL 5000 data output array and analyzed offline. $\mathrm{T}_{\mathrm{I}}, \mathrm{T}_{\mathrm{E}}, \mathrm{PEF}$, and inspiratory tidal volume $\left(\mathrm{V}_{\mathrm{T}}\right)$ were obtained from the flow tracing, whereas inspiratory and expiratory $\mathrm{P}_{\mathrm{aw}}$ and time to reach $90 \%$ of preset inspiratory and expiratory $\mathrm{P}_{\mathrm{aw}}$ ( $\mathrm{T}_{90 \mathrm{I}}$ and $\mathrm{T}_{90 \mathrm{E}}$, respectively) were obtained from the $\mathrm{P}_{\mathrm{aw}}$ tracing.

In bench test 1 , inspiratory and expiratory $\mathrm{P}_{\mathrm{aw}}$ were analyzed to evaluate whether the difference between preset and actual values was in accordance with the $4 \%$ tol- erance limit indicated by the European Commission requirements (51.104-CEI EN 60601-2-12). ${ }^{16}$ To assess variability of each model, the test was performed on 3 machines obtained from the commercial distributors.

In bench test 2, we evaluated the performance of the mechanically assisted cough devices under different simulated conditions. Inspiratory and expiratory Paw, PEF, $\mathrm{V}_{\mathrm{T}}, \mathrm{T}_{90 \mathrm{I}}$, and $\mathrm{T}_{90 \mathrm{E}}$ were determined for each device and compared.

In the user-friendliness test, the time required to perform tasks was measured with a precision stopwatch by a second bioengineer in the laboratory of the Department of Clinical Engineering with extensive knowledge of all 5 mechanically assisted cough devices and awareness of the tasks to be accomplished. For all tasks, the time measurement was interrupted upon achievement of the specific objective or at a maximum limit of $5 \mathrm{~min}$. In addition, the physicians graded the ease of use of each device, both overall and separately for each single task, using a visual analog scale on a $10-\mathrm{cm}$ line marked with 0 on the left for very difficult and 10 on the right for very easy. Finally, the errors made by the physicians during test execution were counted and expressed both as absolute values and percent of the overall actions required during the test.

\section{Statistical Analysis}

Data are expressed as median (interquartile range) unless specified otherwise and were compared by analysis of variance on ranks (Kruskal-Wallis test). The Dunn post hoc test was used to ascertain differences between either selected pairs of conditions (bench test 2) or all mechanically assisted cough devices (user-friendliness test), as appropriate. We considered $P<.05$ to be significant.

\section{Results}

\section{Bench Test 1}

As shown in Figure 1A, the discrepancy between preset and actual inspiratory and expiratory $\mathrm{P}_{\mathrm{aw}}$ was within the $4 \%$ tolerance limits for 2 mechanically assisted cough devices (Nippy and Pulsar) only. Furthermore, all devices but one (Nippy) showed uneven inspiratory and expiratory $\mathrm{P}_{\mathrm{aw}}$ with the 3 machines tested. As shown in Figure 1B, discrepancies were observed between preset and actual $T_{I}$ and $\mathrm{T}_{\mathrm{E}}$. All devices but one (Pulsar) for $\mathrm{T}_{\mathrm{I}}$ and all but 2 devices (Nippy and Pulsar) for $T_{E}$ showed erratic values with the 3 machines tested.

\section{Bench Test 2}

Figure $2 \mathrm{~A}$ shows inspiratory $\mathrm{P}_{\mathrm{aw}}, \mathrm{V}_{\mathrm{T}}$, and $\mathrm{T}_{90 \mathrm{I}}$, and Figure $2 \mathrm{~B}$ shows expiratory $\mathrm{P}_{\mathrm{aw}}, \mathrm{PEF}$, and $\mathrm{T}_{90 \mathrm{E}}$. Inspira- 


\section{Mechanically Assisted Cough Devices}
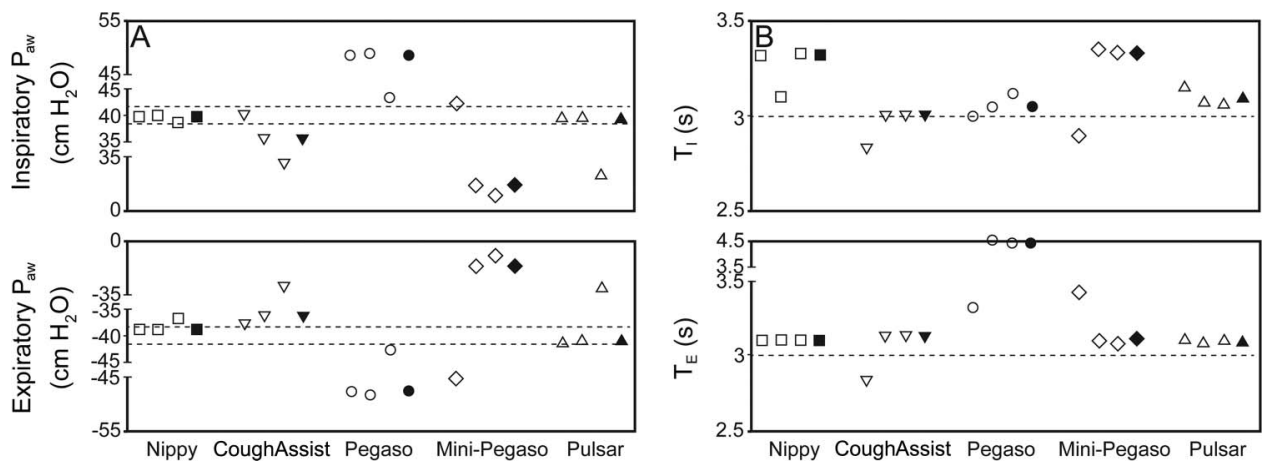

Fig. 1. Discrepancy between preset and actual airway pressures. A: inspiratory and expiratory airway pressure $\left(P_{\text {aww }}\right)$ medians of 5 respiratory cycles obtained with each individual mechanically assisted cough device (white symbols). The median values of the overall 15 measurements (black symbols) are also displayed for each type of device. Dashed lines indicate the $\pm 4 \%$ tolerance limits according to the European Commission regulation for mechanical ventilators. B: inspiratory $\left(T_{1}\right)$ and expiratory $\left(T_{E}\right)$ time medians are shown for each device.

tory $\mathrm{P}_{\mathrm{aw}}$ was significantly affected by mechanical properties with one device only (Pegaso) and to varying extents by the presence of air leaks with the other 4 devices. $\mathrm{V}_{\mathrm{T}}$ was affected by the simulated mechanical properties with the Nippy device and to varying extents by air leaks with the other 4 devices. $T_{90 I}$ was unaffected by mechanical properties or air leaks with the CoughAssist; by mechanical properties with the Pegaso, Mini Pegaso, and Pulsar; and by air leaks with the Nippy. Expiratory $\mathrm{P}_{\mathrm{aw}}$ was affected by mechanical properties with the Pegaso and to varying extents by air leaks with the other 4 devices. PEF was influenced by mechanical properties with the Mini Pegaso and Pulsar and by air leaks with the Nippy, CoughAssist, Pegaso and Mini Pegaso. $\mathrm{T}_{90 \mathrm{E}}$ was affected by mechanical properties with the Mini Pegaso and by air leaks with the other 4 devices.

\section{User-Friendliness Test}

All 10 physicians completed all 4 tasks. Table 2 shows (1) the median (interquartile range) of the time spent by the 10 physicians to accomplish the 4 tasks individually and overall, (2) the scores on the ease of accomplishment of the tasks by the physicians, and (3) the errors made by the physicians during task execution. Overall, the Pegaso and Pulsar showed the shortest and longest times of execution, respectively. In addition, there were wide and significant differences between the mechanically assisted cough devices with respect to the individual tasks. The scores on the ease of use were no different overall and showed significant differences only for the start-up and recognizing-parameters tasks. The CoughAssist resulted in significantly more errors overall, as opposed to the Pegaso $(P=.04)$, Mini Pegaso $(P=.04)$, and Pulsar $(P=.03)$. This was due primarily to the recognizing-parameters task. The Nippy showed no significant difference with respect to all tasks compared with the other devices.
As shown in Figure 3, the overall median time spent to accomplish the 4 tasks by the product specialists using each of the 5 devices (gray bar) was significantly shorter compared with that achieved by the 10 physicians (white bars) $(P=.02)$.

\section{Discussion}

In this study, we found that only 2 of the 5 mechanically assisted cough devices complied with the $4 \%$ tolerance limit for the discrepancy between preset and actual inspiratory and expiratory $\mathrm{P}_{\mathrm{aw}}$. Moreover, for all devices but one, the actual inspiratory and expiratory $\mathrm{P}_{\mathrm{aw}}$ of the 3 machines tested were discrepant. In addition, the performance of the 5 devices was affected differently by the simulated mechanical properties, the air leaks, or both. Finally, the time spent to accomplish 4 tasks (separately and overall) assigned to 10 ICU physicians was largely and significantly different between devices. The ease of accomplishment of the tasks was not significantly different between the devices overall, whereas there were relatively small significant differences between devices with respect to 2 individual tasks (ie, start-up and recognizing parameters).

Our bench study is the first to evaluate and compare several mechanically assisted cough devices. In a previously published bench study comparing the Nippy and CoughAssist operating with varying mechanical properties (but without considering air leaks), PEF was found to be greater with the Nippy. ${ }^{17}$ It is of note that in a previous bench evaluation performed to assess the impact of various artificial airways on the performance of the CoughAssist, the same authors reported quite different PEF values with an identical setup. ${ }^{18}$ In keeping with these contradictory findings, ${ }^{17,18}$ we found uneven inspiratory and expiratory $\mathrm{P}_{\mathrm{aw}}$ (see Fig. 1A) and $\mathrm{T}_{\mathrm{I}}$ and $\mathrm{T}_{\mathrm{E}}$ (see Fig. 1B) between the 3 machines tested for each device. Furthermore, though all 


\section{Mechanically Assisted Cough Devices}

A
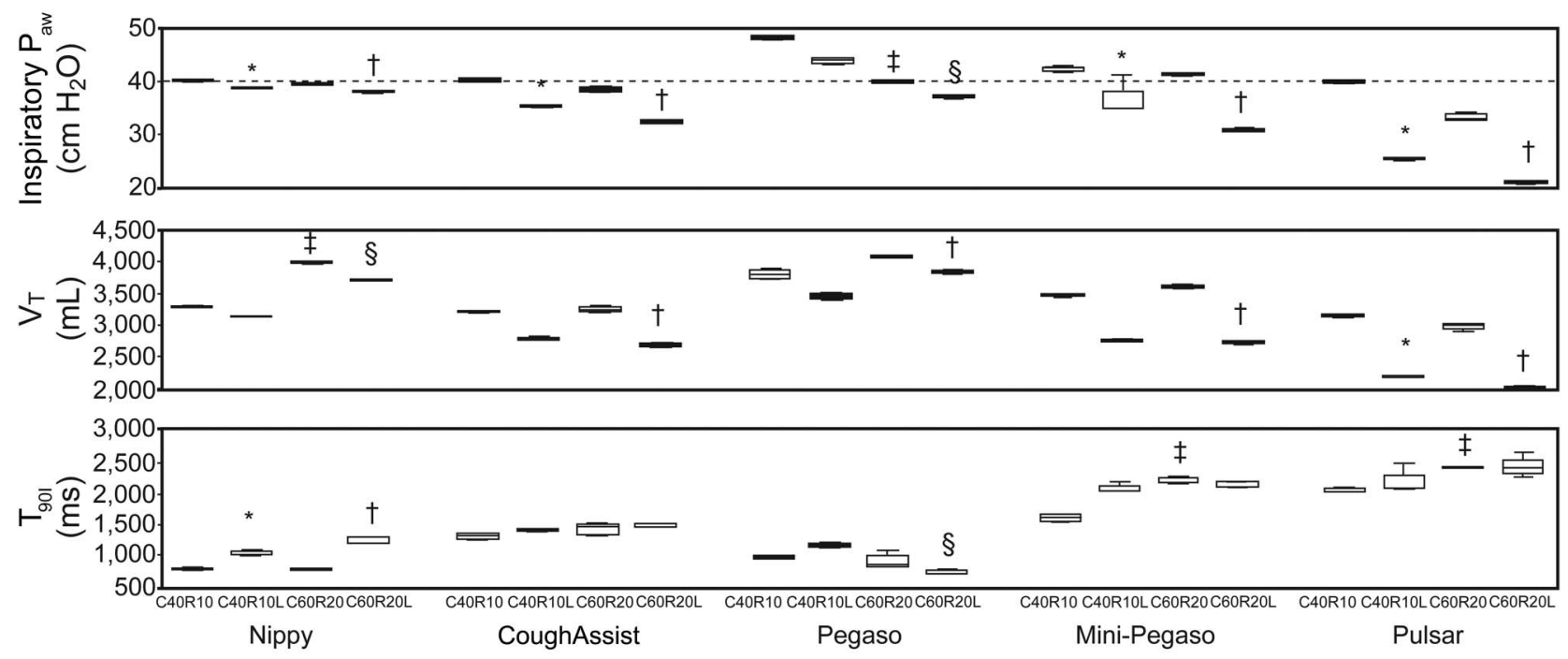

Tested conditions

B
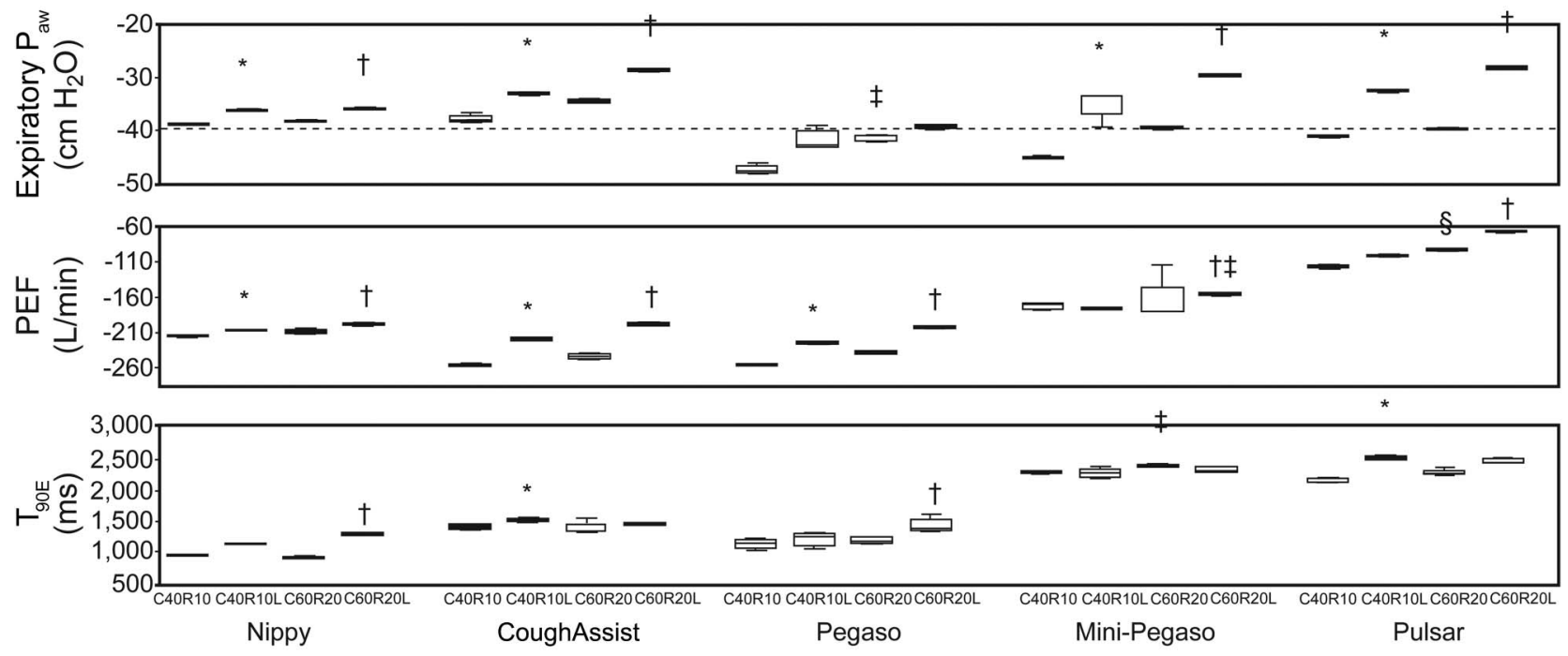

Tested conditions

Fig. 2. Mechanically assisted cough device performance with varying mechanical properties and air leaks. A: Inspiratory airway pressure $\left(P_{a w}\right)$, tidal volume $\left(V_{T}\right)$, and time to reach $90 \%$ of preset inspiratory $P_{a w}\left(T_{901}\right)$ in different simulated conditions. B: Expiratory $P_{\text {aw }}$, peak expiratory flow (PEF), and time to reach $90 \%$ of preset expiratory $\mathrm{P}_{\mathrm{aw}}\left(\mathrm{T}_{90 \mathrm{E}}\right)$ in different simulated conditions. Dashed lines indicate preset inspiratory $(\mathrm{A})$ and expiratory $(\mathrm{B}) \mathrm{P}_{\text {aw }} \cdot{ }^{*} \mathrm{P}<.05$, compliance of $40 \mathrm{~mL} / \mathrm{cm} \mathrm{H}_{2} \mathrm{O}$ and resistance of $10 \mathrm{~cm} \mathrm{H}_{2} \mathrm{O} / \mathrm{L} / \mathrm{s}$ with air leaks $(\mathrm{C} 40 \mathrm{R} 10 \mathrm{~L})$ vs compliance of $40 \mathrm{~mL} / \mathrm{cm} \mathrm{H}_{2} \mathrm{O}$ and resistance of $10 \mathrm{~cm} \mathrm{H} \mathrm{C}_{2} \mathrm{O} / \mathrm{L} / \mathrm{s}$ without air leaks (C40R10). $\uparrow P<.05$, compliance of $60 \mathrm{~mL} / \mathrm{cm} \mathrm{H} \mathrm{H}_{2} \mathrm{O}$ and resistance of $20 \mathrm{~cm} \mathrm{H}_{2} \mathrm{O} / \mathrm{L} / \mathrm{s}$ with air leaks (C60R2OL) vs compliance of $60 \mathrm{~mL} / \mathrm{cm} \mathrm{H}_{2} \mathrm{O}$ and resistance of $20 \mathrm{~cm} \mathrm{H} \mathrm{H}_{2} \mathrm{O} / \mathrm{L} / \mathrm{s}$ without air leaks (C60R20). $\ddagger P<.05$, C60R20 vs C40R10; $\S P<.05$, C60R20L vs C40R10L. (For exact $P$ values, see the supplementary materials at http://www.rcjournal.com.).

5 devices had the European Conformity mark, only 2 devices conformed overall to the European Community $4 \%$ tolerance limit for mechanical ventilators with respect to the difference between preset and actual $\mathrm{P}_{\mathrm{aw}}$. In addition, although the $4 \%$ tolerance limit corresponds in our study to a difference between preset and actual inspiratory and expiratory $\mathrm{P}_{\mathrm{aw}}$ of only $1.6 \mathrm{~cm} \mathrm{H}_{2} \mathrm{O}$ (a relatively small value of limited clinical importance), some machines markedly exceeded the $4 \%$ limit (see Fig. 1A). These discrepancies may be more relevant in particular scenarios, such as when the mechanically assisted cough device is applied with a tracheotomy or endotracheal tube rather than de- 


\section{Mechanically Assisted Cough Devices}

Table 2. Time, Ease of Use, and Errors for Accomplishment of Tasks

\begin{tabular}{|c|c|c|c|c|c|}
\hline & Nippy & CoughAssist & Pegaso & Mini Pegaso & Pulsar \\
\hline \multicolumn{6}{|l|}{ Time, s } \\
\hline Start-up & $13(12-22)$ & $3(2-4)$ & $26(22-34)^{\mathrm{a}}$ & $37(32-58)^{\mathrm{b}}$ & $76(57-111)^{\mathrm{c}, \mathrm{d}}$ \\
\hline Recognizing parameters & $20(18-22)$ & $68(44-84)^{\mathrm{e}}$ & $17(14-19)^{\mathrm{f}}$ & $19(16-38)^{\mathrm{g}}$ & $23(17-30)^{\mathrm{h}}$ \\
\hline Varying settings & $103(91-139)$ & $83(52-113)$ & $67(62-92)$ & $83(63-112)$ & $153(153-154)^{\mathrm{d}, \mathrm{i}, \mathrm{j}}$ \\
\hline Stop & $67(22-91)$ & $7(5-17)^{\mathrm{e}}$ & $5(3-72)^{\mathrm{k}}$ & $8(7-14)^{1}$ & $23(17-62)^{\mathrm{i}}$ \\
\hline Overall & $217(169-269)$ & $151(116-224)$ & $127(105-157)^{\mathrm{m}}$ & $181(125-213)$ & $309(249-354)^{\mathrm{h}, \mathrm{i}}$ \\
\hline \multicolumn{6}{|l|}{ Visual analog scale ease of use, $\mathrm{cm}$} \\
\hline Start-up & $9.4(8.1-9.7)$ & $9.6(9.1-9.9)$ & $7.2(6.6-8.5)^{\mathrm{a}}$ & $7.2(6.3-9.1)^{\mathrm{n}}$ & $5.4(3.4-7.8)^{\mathrm{c}, \mathrm{d}}$ \\
\hline Recognizing parameters & $9.5(8.7-9.8)$ & $7.2(3.7-7.5)^{\mathrm{o}}$ & $9.4(8.3-9.7)^{\mathrm{a}}$ & $9.4(7.7-9.7)^{\mathrm{n}}$ & $8.3(7.0-9.3)$ \\
\hline Varying settings & $9.2(8.4-9.5)$ & $7.0(4.0-8.9)$ & $8.9(8.3-9.4)$ & $8.1(6.6-8.8)$ & $7.3(5.2-8.6)$ \\
\hline Stop & $8.9(7.6-9.2)$ & $9.3(5.9-9.7)$ & $9.4(8.4-9.7)$ & $8.8(8.3-9.7)$ & $6.4(4.7-9.0)$ \\
\hline Overall & $8.8(7.4-9.3)$ & $7.7(6.4-9.1)$ & $8.8(7.9-9.5)$ & $8.9(7.5-9.3)$ & $6.9(4.6-8.7)$ \\
\hline \multicolumn{6}{|l|}{ Errors, \% (n) } \\
\hline Start-up & $0(0),(0)$ & $0(0),(0)$ & $0(0),(0)$ & $0(0),(0)$ & $0(0),(0)$ \\
\hline Recognizing parameters & $0(0-20),(4)$ & $40(15-45),(18)$ & $0(0),(1)^{\mathrm{p}}$ & $0(0),(2)^{\mathrm{n}}$ & $0(0),(0)^{\mathrm{h}}$ \\
\hline Varying settings & $0(0-30),(7)$ & $0(0-40),(10)$ & $0(0),(0)$ & $0(0),(0)$ & $0(0),(1)$ \\
\hline Stop & $0(0),(0)$ & $0(0),(0)$ & $0(0),(0)$ & $0(0),(0)$ & $0(0),(0)$ \\
\hline Overall & $0(0-21),(11)$ & $21(12-31),(28)$ & $0(0),(1)^{\mathrm{p}}$ & $0(0),(2)^{\mathrm{n}}$ & $0(0),(1)^{\mathrm{h}}$ \\
\hline $\begin{array}{l}\text { Data are expressed as median (interquartile range). } \\
{ }^{\mathrm{a}} P=.02 \text { Pegaso vs CoughAssist } \\
{ }^{\mathrm{b}} P=.001 \text { Mini Pegaso vs CoughAssist } \\
{ }^{\mathrm{c}} P=.001 \text { Pulsar vs Nippy } \\
{ }^{\mathrm{d}} P=.001 \text { Pulsar vs CoughAssist } \\
{ }^{\mathrm{e}} P=.01 \text { CoughAssist vs Nippy } \\
{ }^{\mathrm{e}} P<.001 \text { Pegaso vs CoughAssist } \\
{ }^{\mathrm{f}} P=.01 \text { Mini Pegaso vs CoughAssist } \\
{ }^{\mathrm{g}} P=.03 \text { Pulsar vs CoughAssist }\end{array}$ & & $\begin{array}{l}{ }^{\mathrm{i}} P=.00 \\
{ }^{\mathrm{j}} P=.02 \\
{ }^{\mathrm{k}} P=.00 \\
{ }^{1} P=.02 \\
{ }^{\mathrm{m}} P=.02 \\
{ }^{\mathrm{n}} P=.04 \\
{ }^{\circ} P=.00 \\
{ }^{\mathrm{o}} P=.04\end{array}$ & $\begin{array}{l}\text { sar vs Pegaso } \\
\text { ir vs Mini Pegaso } \\
\text { raso vs Nippy } \\
\text { Pegaso vs Nippy } \\
\text { aso vs Nippy } \\
\text { Pegaso vs CoughAssist } \\
\text { ughAssist vs Nippy } \\
\text { so vs CoughAssist }\end{array}$ & & \\
\hline
\end{tabular}

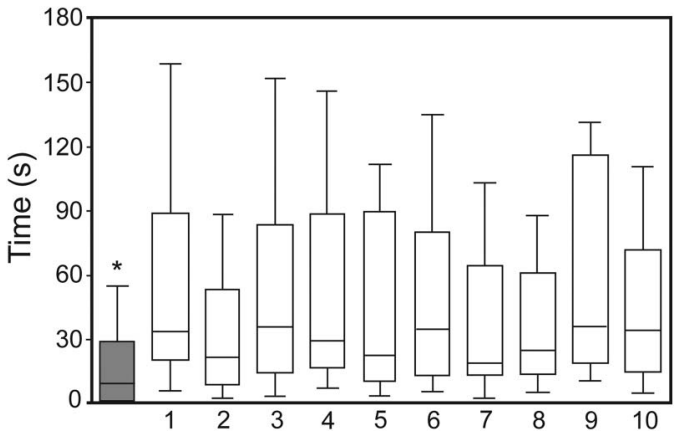

Fig. 3. Time for performing all the tests on all mechanically assisted cough devices by ICU physicians The graph shows the overall median time spent to accomplish all tasks by the product specialists (grey bar) compared with 10 ICU physicians (white bars). ${ }^{*} P=.02$, product specialists vs physicians.

livered via a face mask or mouthpiece. Furthermore, we do not know whether the variance between actual and preset values is greater or less marked at insufflation-exsufflation pressure settings other than +40 to $-40 \mathrm{~cm} \mathrm{H}_{2} \mathrm{O}$.

In a bench test of one mechanically assisted cough device (CoughAssist) at 3 different preset inspiratory and expiratory $\mathrm{P}_{\mathrm{aw}}$ with 4 simulated mechanical properties, Guérin et $\mathrm{al}^{18}$ showed that varying the size of the artificial airway (ie, the additional airway resistance imposed by the tube) affects PEF, which is the strongest indicator of cough efficacy. Our study expands this observation, demonstrating that the performance of these devices is affected by the mechanical properties of the respiratory system and by the presence of air leaks. In fact, we found not only PEF, but also $\mathrm{V}_{\mathrm{T}}$, the actual inspiratory and expiratory $\mathrm{P}_{\mathrm{aw}}, \mathrm{T}_{90 \mathrm{I}}$, and $\mathrm{T}_{90 \mathrm{E}}$ to fluctuate with all mechanically assisted cough devices, although to remarkably varying extents. As shown in Figure $4, V_{T}$, actual inspiratory and expiratory $\mathrm{P}_{\mathrm{aw}}, \mathrm{T}_{90 \mathrm{I}}$, and $\mathrm{T}_{90 \mathrm{E}}$ are all determinants of PEF.

Gonzalez-Bermejo et al ${ }^{19}$ reported the limited userfriendliness of home ventilators and stressed the importance of this considering the increasing number of medical and nonmedical health-care professionals required to manage the technical aspects of these machines when caring for patients receiving home ventilation. The authors found that for most ventilators, the ICU physicians were slower than the specialist technician in completing the required tasks. Furthermore, the physicians scored the overall ease of use as no different between ventilators. With a similar study design, the present study extends those observations to mechanically assisted cough devices. The time taken by each task differed between devices, and overall, ICU physicians were slower than the product specialist. Also, consistent with the former study, physicians scored ease of 


\section{Mechanically Assisted Cough Devices}

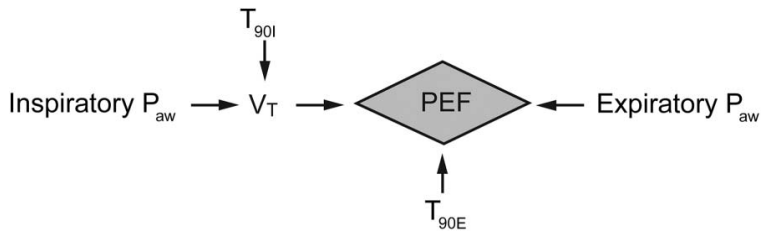

Fig. 4. Determinants of peak expiratory flow (PEF), which is the strongest indicator of cough efficacy. The magnitude of PEF is directly influenced by the pressure applied to the airway opening $\left(P_{a w}\right)$ during the expiratory phase, the time to reach $90 \%$ of preset expiratory $P_{a w}\left(T_{90 E}\right)$, and the volume insufflated during the inspiratory phase (tidal volume $\left[V_{\mathrm{T}}\right]$ ), corresponding to the pre-tussive volume and resulting from the extent of the inspiratory $P_{a w}$ and the speed of achievement of the time to reach $90 \%$ of preset inspiratory $\mathrm{P}_{\mathrm{aw}}\left(\mathrm{T}_{901}\right)$.

use overall as no different between devices. Importantly, however, the only device with an analog interface (CoughAssist) produced the highest incidence of errors in the recognizing-parameters task and received the lowest score.

Our study has limitations. First, it has the intrinsic limitation of any bench evaluation that attempts in a strictly controlled environment to simulate situations that are definitely more complex and dynamically variable in the clinical setting. Although no recommendation or specific requirement exists for bench evaluations, ${ }^{20}$ in particular for these devices, we attempted to mimic the most common clinical settings and scenarios. It is clear that the huge discrepancies we found between preset and actual values and the inhomogeneous behavior of machines of the same model indicate that some mechanically assisted cough devices might not produce PEF high enough to achieve adequate airway clearance. ${ }^{1,9,21}$ Second, we extended the $4 \%$ tolerance limit (originally intended for mechanical ventilators) to mechanically assisted cough devices, which may be considered arbitrary and potentially unfair. Lacking specific criteria, we chose the evaluation regulations in force for the instruments more closely resembling these devices. Third, a blinded assessment of mechanically assisted cough devices is not feasible; nonetheless, neither the bioengineer who performed the bench testing nor the physicians involved in the user-friendliness test had previous experience with any of the devices under evaluation. Fourth, we differ from North America but are similar to many other European countries in that we do not have respiratory therapists in our hospitals and thus performed our userfriendliness evaluation by interviewing ICU physicians. Therefore, the results of our evaluation might not be applicable to other health-care professionals or nonprofessional caregivers. Considering ICU physicians' familiarity with similar but more complex devices such as mechanical ventilators, the user-friendliness of mechanically assisted cough devices might be even worse for other categories of users. Finally, we tested all of the devices available in our country at the time the study was performed. It is notable that only one device is presently available for clinical use in North America. We are aware that some new mechanically assisted cough devices have since been introduced in the market, and the manufacturers have updated some of those evaluated here. Although we share this limitation with any study evaluating medical devices, we believe that the message of this study remains valid for both clinicians and manufacturers.

\section{Conclusions}

The performance of different mechanically assisted cough devices was extremely variable, even between machines of the same model, and is affected by respiratory system impedance and air leaks. The time taken to set up and operate the devices and the number of procedural errors made by the ICU physicians were high. These findings indicate that the devices are not interchangeable and that the settings should be targeted for each patient with the specific machine utilized. A substantial improvement in reliability, reproducibility of performance, and userfriendliness is advised.

\section{REFERENCES}

1. Bach JR, Saporito LR. Criteria for extubation and tracheostomy tube removal for patients with ventilatory failure. A different approach to weaning. Chest 1996;110(6):1566-1571.

2. Bach JR, Gonçalves MR, Hon A, Ishikawa Y, De Vito EL, Prado F, Dominguez ME. Changing trends in the management of end-stage neuromuscular respiratory muscle failure: recommendations of an international consensus. Am J Phys Med Rehabil 2013;92(3):267277.

3. Tzeng AC, Bach JR. Prevention of pulmonary morbidity for patients with neuromuscular disease. Chest 2000;118(5):1390-1396.

4. Toussaint M. The use of mechanical insufflation-exsufflation via artificial airways. Respir Care 2011;56(8):1217-1219.

5. Sancho J, Servera E, Díaz J, Marín J. Efficacy of mechanical insufflation-exsufflation in medically stable patients with amyotrophic lateral sclerosis. Chest 2004;125(4):1400-1405.

6. Bach JR. Mechanical insufflation-exsufflation. Comparison of peak expiratory flows with manually assisted and unassisted coughing techniques. Chest 1993;104(5):1553-1562.

7. Chatwin M, Ross E, Hart N, Nickol AH, Polkey MI, Simonds AK. Cough augmentation with mechanical insufflation/exsufflation in patients with neuromuscular weakness. Eur Respir J 2003;21(3):502508 .

8. Mustfa N, Aiello M, Lyall RA, Nikoletou D, Olivieri D, Leigh PN, et al. Cough augmentation in amyotrophic lateral sclerosis. Neurology 2003;61(9):1285-1287.

9. Bach JR, Gonçalves MR, Hamdani I, Winck JC. Extubation of patients with neuromuscular weakness: a new management paradigm. Chest 2010;137(5):1033-1039.

10. Gonçalves MR, Honrado T, Winck JC, Paiva JA. Effects of mechanical insufflation-exsufflation in preventing respiratory failure after extubation: a randomized controlled trial. Crit Care 2012;16(2):R48.

11. Bach JR, Rajaraman R, Ballanger F, Tzeng AC, Ishikawa Y, Kulessa $R$, Bansal T. Neuromuscular ventilatory insufficiency: effect of home 


\section{Mechanically Assisted Cough Devices}

mechanical ventilator use $\mathrm{v}$ oxygen therapy on pneumonia and hospitalization rates. Am J Phys Med Rehabil 1998;77(1):8-19.

12. Vitacca M, Paneroni M, Trainini D, Bianchi L, Assoni G, Saleri M, et al. At home and on demand mechanical cough assistance program for patients with amyotrophic lateral sclerosis. Am J Phys Med Rehabil 2010;89(5):401-406.

13. Chatwin M, Simonds AK. The addition of mechanical insufflation/ exsufflation shortens airway-clearance sessions in neuromuscular patients with chest infection. Respir Care 2009;54(11):1473-1479.

14. Blakeman TC, Rodriquez D Jr, Hanseman D, Branson RD. Bench evaluation of 7 home-care ventilators. Respir Care 2011;56(11):17911798.

15. Navalesi P, Frigerio P. Cough assistance in mechanically ventilated neuromuscular patients. In: Vincent JL. Update in intensive care. Berlin: Springer-Verlag; 2004; 345-352.

16. Council of the European Communities. Council Directive 93/42/EEC of 14 June 1993 concerning medical devices. http://eur-lex.europa.
eu/LexUriServ/LexUriServ.do?uri=CONSLEG:1993L0042: 20071011:en:PDF. Accessed March 17, 2015.

17. Porot V, Guérin C. Bench assessment of a new insufflation-exsufflation device. Respir Care 2013;58(9):1536-1540.

18. Guérin C, Bourdin G, Leray V, Delannoy B, Bayle F, Germain M, Richard JC. Performance of the CoughAssist insufflation-exsufflation device in the presence of an endotracheal tube or tracheostomy tube: a bench study. Respir Care 2011;56(8):1108-1114.

19. Gonzalez-Bermejo J, Laplanche V, Husseini FE, Duguet A, Derenne JP, Similowski T. Evaluation of the user-friendliness of 11 home mechanical ventilators. Eur Respir J 2006;27(6):1236-1243.

20. Olivieri C, Costa R, Conti G, Navalesi P. Bench studies evaluating devices for non-invasive ventilation: critical analysis and future perspectives. Intensive Care Med 2012;38(1):160-167.

21. Smina M, Salam A, Khamiees M, Gada P, Amoateng-Adjepong Y, Manthous CA. Cough peak flows and extubation outcomes. Chest 2003;124(1):262-268.

This article is approved for Continuing Respiratory Care Education credit. For information and to obtain your CRCE

(free to AARC members) visit 